Project Number 86890

\title{
A RESOLUTION ANALYSIS OF TWO GEOPHYSICAL IMAGING METHODS FOR CHARACTERIZING AND MONITORING HYDROLOGIC CONDITIONS IN THE VADOSE ZONE
}

This project is a follow up on Project 70267 titled: A Hydrologic-Geophysical Method for Characterizing Flow and Transport Processes within the Vadose Zone. As such, this annual report is a slightly modified version of the report submitted in 2003 for 70267.

$6 / 4 / 03$

\section{RESEARCH OBJECTIVE}

The objective of this study is to to characterize and analyze in-situ flow and transport within the vadose zone during a mid-scale hydrologic infiltration experiment. This project has employed numerical and experimental tools developed under a previously funded EMSP proposal (project number 55332) to provide 3-D unsaturated hydrologic property distributions. In the present project, geophysical imaging techniques have been employed to track analogue contaminant plumes. The results are providing a better understanding of transport modes including the influence of natural heterogeneities and man-made structures within the vadose zone at DOE sites. In addition the data is providing checks against which numerical flow and transport simulations can be compared.

\section{RESEARCH PROGRESS AND IMPLICATIONS:}

As of the 45 month of this originally funded 36 month project we are in the final stages of research. The additional time has been provided via a 1-year no cost agreement with a final report due in December of 2003. We have completed a two-stage infiltration experiment at the Sandia/Tech Vadose Zone facility (STVZ) in Socorro, New Mexico to simulate contaminant transport in a heterogeneous vadose zone. All research activities at the site ceased as of August 2002 and currently we are processing and analyzing both geophysical and hydrologic data from the two salt-tracer experiments. In addition, we are in the process of transferring the STVZ site to New Mexico Institute of Mining and Technology's Earth and Environmental Science Hydrology Department where the site will be utilized as a teaching facility.

To briefly review the sequence of infiltration events at the STVZ, infiltration with tap water began March 11, 1999. For 816 days tap water was infiltrated into a 9 panel infiltrometer at a rate less than the measured saturated hydraulic conductivity $(2.7 \mathrm{~cm} /$ day $)$ during which time subsurface conditions were monitored with a variety of hydrologic and geophysical instrumentation. Geophysical measurements included cross-well ground penetrating radar (XBGPR) and electrical resistivity tomography (ERT), which provided a series of detailed two and three dimensional images, respectively, showing initial moisture content distributions, delineating clay beds from clay poor beds, and imaging the development of the wetted bulb over time. Also neutron moisture and induction well log data were collected in several PVC cased boreholes in order to validate the imaging results. This tap water infiltration event provided a steady-state flow field upon which the more recent salt tracer experiments were superimposed.

For 226 days a 1024-ppm NaCl solution $(2,750 \mathrm{uS} / \mathrm{cm})$ was introduced into three of nine infiltration panels for first salt infiltration event while continuing with tap water infiltration to the other six panels. For the second tracer experiment, the $\mathrm{NaCl}$ solution concentration was increased to $6900-\mathrm{ppm}(10,000 \mathrm{uS} / \mathrm{cm})$ and infiltrated for 138 days. The two tracer events were separated by a tap water flush lasting 53 days; the tap water had a conductivity of $900 \mathrm{uS} / \mathrm{m}$. To maintain steady state conditions, total water flow to the infiltrometer remained at $2.7 \mathrm{~cm} / \mathrm{day}$. 
Several advancements have been made in 3D ERT processing and interpretation over the past year. First we implemented a method of correcting for the effects of subsurface temperatures on electrical resistivity tomography images. Through subsurface thermocouple data we determined that substantial annual changes in the subsurface temperatures occur due to both direct conductive heating of the subsurface as well as by advective transport of heat through the infiltrating water. Using an array of subsurface thermocouples we observed annual temperature changes of $17 \mathrm{C}$ at a depth of $2 \mathrm{~m}$ and significant changes as deep as $8 \mathrm{~m}$. These changes in temperature in turn change the electrical conductivity of the subsurface. Because subsurface temperatures were found to be higher in early October than in February, if corrections are not applied the imaged anomalies are larger than they should be in October and smaller in December. The ERT images that result from applying the correction to data collected during the second trace experiment more clearly show the strong influence of the layering on the subsurface transport. The tracer expands and moves laterally in and the finer grained layers and constricts in coarsegrained layers, particularly near the interfaces between the coarse-grained layers and underlying fine-grained layers.

A second advancement has been the development of a joint hydro-geophysical inverse approach to directly estimate water content distribution from ERT data. Unlike classical ERT inverse approaches, the new approach constrains the inversion by including prior knowledge of geological and moisture content distribution structures in a field, point measurements of electrical resistivity and voltages, and measurement of moisture contents from other instruments (e.g., neutron probes). Classical approaches for converting electrical resistivity fields to water content distributions rely on a constant relationship between resistivity and water content. Core samples collected from the STVZ filed site were analyzed and found to exhibit significant spatial variability. This spatially varying resistivity-moisture relationship was shown to cause great uncertainty in the estimates of change of moisture content based on estimated change in electrical resistivity.

Subsequently, we developed an algorithm to include the relationship measured at various locations in the field to improve our estimates of the moisture content distribution. The usefulness of the new approach was illustrated by directly estimating moisture distribution in a hypothetical 3 -D vadose zone during an infiltration event. Results show that this approach can reproduce the general pattern of the true water content distribution, and that the incorporation of moisture measurements into to the model significantly improves the estimates. Also, we developed a stochastic data fusion technology that integrates ERT surveys and a hydrologic inversion model to enhance images of moisture content distributions, and to improve characterization of the vadose zone.

Finally, induced polarization data collected during ERT data acquisition earlier in this experiment were seldom of sufficient quantity to be interpreted. Recently under this project, improvements in data collection methods and data processing have made 3D imaging of this data feasible. We have carried out initial analysis of the cross-borehole induced-polarization data collected during the tracer injections which show that zones of highest chargeability correspond to interbedded clay and sand layers between the clay layers.

As we expected, the XBGPR imaging method indicated that attenuation increases with the introduction of the sodium chloride solution. During the first saltwater infiltration we observed an anomalous region of higher attenuation, indicating the location of the saltwater plume, appearing after 14 days of saltwater infiltration. The attenuation anomaly grows larger, with the attenuation increase due to the plume exceeding $0.3 \mathrm{~Np} / \mathrm{m}$ after 158 days of infiltration. The location of this anomalous attenuation region correlates to a zone of higher moisture content at the same depth during the first infiltration stage, suggesting that at least along the profile across which the XBGPR data were collected, the saltwater plume stopped and perched on top of a hydrogeological barrier. 
XBGPR images generated from data collected during the second stage initially show similar results to that of the first injection, with main body of the salt-water plume staying above $3 \mathrm{~m}$ depth during the first 23 days. After this point in time the plume migrates deeper, and seems to follow a migration pathway that connects regions of high water content in the XBGPR velocity-derived moisture content images. Results during this second experiment compare very well both with the lower resolution ERT images as well as induction logs collected in the same boreholes as the GPR data.

\section{PLANNED ACTIVITIES}

To wrap up the XBGPR portion of project 70267, as well as to lead into this new EMSP project 86890 , we are performing $2 \mathrm{D}$ unsaturated flow modeling that roughly mimics the hydrogeology at the site along the XBGPR profile. The resulting time-varying hydrogeologic property fields are then converted to geophysical fields, and synthetic XBGPR data sets computed using geophysical modeling software. These synthetic GPR data sets will then be inverted and the resulting images examined to define those aspects of the infiltrations that can be resolved via XBGPR imaging, and those that are artifacts of the geophysical imaging process. A paper will be prepared on these results. We are also emphasizing completion of ERT data analysis and writing of one or two additional papers. It is anticipated that the first of these papers will discuss the application anisotropic interpretation method to monitoring of the infiltration and saline trace studies at the STVZ, while the second the analysis of the induced polarization data from the site.

As part of project 86890 , we have begun initial tests and updates of codes that will be used to carry out very high-density forward modeling of synthetic models derived from 2D and 3D numerical studies of the infiltration and tracer experiments. We have also made progress towards developing 6-layer, 2 and 3-dimensional property fields based on the vertical distribution of properties from continuous cores collected at the field site and we are in the process of performing preliminary and 3-D forward simulations with Tuff- 2 and PorSalsa. These preliminary studies are aimed at identifying optimal grid resolutions for a variety of initial conditions and a range of hydraulic properties.

\section{INFORMATION ACCESS}

Published Peer Reviewed Journal Articles

1. Alumbaugh, D. L., Chang, P.Y., Paprocki, L., Brainard, J. R., Glass, R. J., and Rautmann, C., 2002, Estimating moisture contents using cross-borehole ground penetrating radar; a study of accuracy, repeatability and resolution in context of an infiltration experiment; Water Resources Research, 38,1309.

2. Yeh, T.-C. J., S. Liu, R. J. Glass, K. Baker, J.R. Brainard, D. Alumbaugh, and D. LaBrecque, A geostatistically based inverse model for electrical resistivity surveys and its applications to vadose zone hydrology, Water Resour. Res., 38(12), 1278, doi: 10.1029/2001WR001204, 2002.

3. Yeh, T.-C. J. and J. Simunek, Stochastic fusion of information for characterizing and monitoring the vadose zone, Vadose Zone Journal, 1:207-221, 2002.

Tentatively Accepted Peer Reviewed Articles, or Articles under Review

1. Chang, P. Y., Alumbaugh, D., Brainard, J., and Hall, L., 2003, The application of ground penetrating radar attenuation tomography in a vadose zone infiltration experiment; submitted for review to, and tentatively accepted by Journal of Contaminant Hydrology.

2. LaBrecque, D., Stubben, M., Alumbaugh. D., and Chang P.Y, and Brainard, J., 2003, Comparison of ERT, GPR, Neutron, and EM-39 Monitoring of an Infiltration Experiment; submitted for publication in a new book on Hydrogeophysics, Hubbard and Rubin, Ed. 
1. Chang, P. Y., Alumbaugh, D., Brainard, J., and Hall, L., 2003, Long term monitoring of a two stage salt infiltration experiment using cross borehole ground penetrating radar tomography; to be submitted to Water Resources Research.

2. LaBrecque, D., and Stubben, M., and Hall, L., 2003, Tracking of a saline tracer in the vadose zone using electrical resistivity tomography; to be submitted to Water Resources Research.

\section{Conference Proceedings}

1. Chang, P. Y., Alumbaugh, D., Brainard, J., and Hall, L., 2002, Using cross borehole ground penetrating radar attenuation tomography for characterizing soil properties in the vadose zone during a two-stage infiltration test; Presented at the 2001 Annual Meeting of the Society of Exploration Geophysicists, September of 2002, Salt Lake City, Utah.

2. LaBrecque, D., Sharp, R., Stubben, M., and Hall, L., 2003,_Monitoring a saline tracer using 3D electrical impedance tomography; Presented at the Symposium on the Application of Geophysics to Environmental and Engineering Problems, April of 2003, San Antonio, Texas 